\title{
Ethnic and Gender Disparities in the Uptake of Transcatheter Aortic Valve Replacement in the United States
}

\author{
Ayman Elbadawi (D) - Syed Yaseen Naqvi · Islam Y. Elgendy • \\ Mohamed F. Almahmoud · Mohamed Hamed · Hesham Abowali • \\ Gbolahan O. Ogunbayo · Hani Jneid · Khaled M. Ziada
}

Received: May 15, 2019 / Published online: June 25, 2019

(C) The Author(s) 2019

\section{ABSTRACT}

Introduction: Little is known about ethnic and gender disparities for transcatheter aortic valve replacement (TAVR) procedures in the United States.

Methods: We queried the Nationwide Inpatient Sample (NIS) database (2011-2014) to identify patients who underwent TAVR. We described the temporal trends in the uptake of TAVR procedures among various ethnicities and genders.

Results: Our analysis identified 39,253 records; 20,497 (52.2\%) were men and 18,756 (47.8\%)

Enhanced Digital Features To view enhanced digital features for this article go to https://doi.org/10.6084/ m9.figshare.8256056.

A. Elbadawi $(\varangle) \cdot$ M. F. Almahmoud · M. Hamed Department of Cardiovascular Medicine, University of Texas Medical Branch, Galveston, TX, USA e-mail: amelbada@utmb.edu

\section{S. Y. Naqvi}

Department of Cardiology, University of Rochester Medical Center, Rochester, NY, USA

I. Y. Elgendy

Division of Cardiovascular Medicine, University of Florida, Gainesville, FL, USA

H. Abowali · G. O. Ogunbayo - K. M. Ziada Department of Cardiovascular Medicine, University of Kentucky, Lexington, KY, USA

H. Jneid

Division of Cardiovascular Medicine, Baylor College of Medicine, Houston, TX, USA were women. Among all TAVRs, 87.2\% were Caucasians, 3.9\% were African Americans (AA), $3.7 \%$ were Hispanics, and $5.2 \%$ were of other ethnicities. We found a significant rise in the trend of TAVRs in all groups: in Caucasian men (coefficient $=0.946, \quad p<0.001$ ), $\quad$ Caucasian women $\quad$ coefficient $=0.985, \quad p<0.001), \quad$ AA men (coefficient $=0.940, \quad p<0.001$ ), AA women (coefficient $=0.864, p<0.001$ ), Hispanic men (coefficient $=0.812, p=0.001$ ), Hispanic women (coefficient $=0.845, p<0.001$ ). Hence, the uptrend was most significant among Caucasian women, and relatively least significant among Hispanic men. Multivariate regression analysis was conducted to evaluate inhospital mortality among different groups after adjusting for demographics and baseline characteristics. After multivariable regression for baseline characteristics overall, the in-hospital mortality per 100 TAVRs was highest among Hispanic men $5.5 \%$, followed by Caucasian women 5.0\%, Hispanic women $4.6 \%$, AA women $3.7 \%$, AA men $3.4 \%$, and Caucasian men $3.38 \%$ (adjusted $p$ value $=0.004$ ).

Conclusions: In this observational study, we demonstrated that there is evidence of ethnic and gender differences in the overall uptake and adjusted mortality of TAVRs in the United States.

Keywords: Gender disparities; Racial disparities; Transcatheter aortic valve replacement 
Transcatheter aortic valve replacement (TAVR) emerged as alternative to surgical replacement for patients with severe aortic stenosis [1-3]. However, little is known about ethnic and gender disparities for TAVR procedures in the United States. This study aimed to evaluate the temporal changes in the uptake of TAVR procedures among the major ethnic groups.

Using the Nationwide Inpatient Sample (NIS) database years 2011-2014, we identified patients who underwent TAVR procedures using International Classification of Diseases procedure code-9; (trans-femoral 35.05 and trans-apical 35.06). Using linear logistic regression analysis, we described the temporal trends in number of TAVR procedures and mortality among various ethnicities and genders. Effect sizes were expressed using co-efficient of regression. Multivariable regression analysis was conducted to compare in-hospital mortality among different study groups. The model included the following variables: age, hypertension, diabetes mellitus, congestive heart failure, chronic lung disease, chronic kidney disease (CKD), obesity, anemia, hypothyroidism, liver disease, fluid/electrolytes abnormalities, peripheral vascular disease, pulmonary circulation disorders, smokers, history of PCI, history of coronary artery bypass grafting, prior MI, and access route for TAVR.

From 2011 to $2014,42,189$ records underwent TAVR. After excluding records with missing data regarding ethnicity (2936), the final cohort included 39,253 records; 20,497 (52.2\%) were men and 18,756 (47.8\%) were women. Among all TAVRs, 34,229 (87.2\%) were Caucasians, 1527 (3.9\%) were African Americans (AA), 1471 (3.7\%) were Hispanics and 2027 (5.2\%) were of other ethnicities. Among Caucasians, 18,023 (52.7\%) were men and 16,206 (47.3\%) were women, among AA ethnicity 589 $(38.6 \%)$ were men and 937 (61.4\%) were women, while among Hispanics 825 (56.1\%) were men and 646 (43.9\%) were women. Baseline characteristics for different study groups are outlined in Table 1.

From 2011 to 2014 , there was an increase in TAVRs in Caucasian men from 493 in the 2011 quarter (q) 4 to 2470 in 2014-q4 with a significant change of trend (coefficient $=0.946$, $p<0.001)$, and in Caucasian women from 381 in 2011-q4 to 2280 in 2014-q4 (coefficient $=0.985, p<0.001)$. Among AA men, TAVRs increased from 11 in 2011-q4 to 85 in 2014-q4 (coefficient $=0.940, p<0.001$ ), and in AA women TAVRs increased from 37 in 2011-q4 to 140 in 2014-q4 (coefficient $=0.864$, $p<0.001)$. In Hispanic men, there was an increase in TAVRs from 11 in 2011-q4 to 100 in 2014-q4 (coefficient $=0.812, p=0.001$ ), while in Hispanic women, TAVRs increased from 11 in 2011-q4 to 90 in 2014-q4 (coefficient $=0.845$, $p<0.001$ ) (Fig. 1). Hence, the uptrend was most significant among Caucasian women, and relatively least significant among Hispanic men.

Multivariate regression analysis was conducted to evaluate in-hospital mortality among different groups after adjusting for demographics and baseline characteristics. Overall, the inhospital mortality per 100 TAVRs was highest among Hispanic men 5.5\% (45/825), followed by Caucasian women $5.0 \%(804 / 15,402)$, Hispanic women $4.6 \%(30 / 646)$, AA women $3.7 \%$ (35/937), AA men 3.40\% (20/589), and Caucasian men $3.38 \%(610 / 18,023)$ (adjusted $p$ value $=0.004)$. Temporal changes in the inhospital mortality among different groups are outlined in Fig. 1. Overall, there was no significant change in the trends, despite some numerical differences along the years.

In this observational study, we demonstrated that there is evidence of ethnic and gender differences in the overall uptake of TAVRs in the US. According to the United States Census Bureau, AA and Hispanics represent 13\% and $17.1 \%$ of the general population, respectively [5]. However, in our study, they only represented $3.9 \%$ and $3.7 \%$ of the TAVR procedures, respectively. We have demonstrated a significant uptrend in the number of TAVRs in all groups, which was most significant in Caucasian women, and least in Hispanic men. Data from the Society of Thoracic Surgeons/American College of Cardiology Transcatheter Valve Therapy (TVT) have reported ethnic differences in the uptake of TAVRs in the United States [4]. In their report including 26,378 TAVRs from 2012 to 2014, the majority were Caucasians (93.8\%) and AA represented only 3.8\% of all TAVRs [4]. The present study extends our 
Table 1 Baseline characteristics among different study groups

\begin{tabular}{|c|c|c|c|c|c|c|c|c|c|c|c|c|c|}
\hline \multirow[t]{2}{*}{ Characteristics } & \multicolumn{2}{|c|}{$\begin{array}{l}\text { White } \\
\text { females } \\
(n=16,206)\end{array}$} & \multicolumn{2}{|c|}{$\begin{array}{l}\text { White males } \\
(n=18,023)\end{array}$} & \multicolumn{2}{|c|}{$\begin{array}{l}\text { AA } \\
\text { females } \\
(n=937)\end{array}$} & \multicolumn{2}{|c|}{$\begin{array}{l}\text { AA males } \\
(n=589)\end{array}$} & \multicolumn{2}{|c|}{$\begin{array}{l}\text { Hispanic } \\
\text { females } \\
(n=646) \\
\end{array}$} & \multicolumn{2}{|c|}{$\begin{array}{l}\text { Hispanic } \\
\text { males } \\
(n=809)\end{array}$} & \multirow[t]{2}{*}{$P$ value } \\
\hline & $\bar{N}$ & $\%$ & $\bar{N}$ & $\%$ & $\bar{N}$ & $\%$ & $\bar{N}$ & $\%$ & $\bar{N}$ & $\%$ & $\bar{N}$ & $\%$ & \\
\hline Hyper & 13,006 & 80.3 & 14,195 & 78.8 & 788 & 84.0 & 474 & 80.5 & 526 & 81.4 & 679 & 82.3 & $<0.0$ \\
\hline Diabe & 5088 & 31.4 & 6354 & 35.3 & 424 & 45.3 & 240 & 40.7 & 295 & 45.7 & 384 & 46.6 & $<0.00$ \\
\hline Heart failure & 2015 & 12.4 & 2014 & 11.2 & 140 & 14.9 & 80 & 13.6 & 75 & 11.6 & 90 & 10.9 & $<0.001$ \\
\hline Chror & 5300 & 32.7 & 6298 & 34.9 & 269 & 28.7 & 184 & 31.2 & 196 & 30.3 & 259 & 31.4 & $<0.00$ \\
\hline CKD & 4595 & 28.4 & 7248 & 40.2 & 390 & 41.6 & 375 & 63.6 & 196 & 30.3 & 400 & 48.5 & $<0.001$ \\
\hline Obesity & 2594 & 16.0 & 2046 & 11.4 & 240 & 25.6 & 80 & 13.6 & 120 & 18.6 & 75 & 9.1 & $<0.00$ \\
\hline hro & 4436 & 27.4 & 4 & 24.0 & 343 & 36.6 & 230 & 39.0 & 201 & 31.1 & 250 & 30.3 & $<0.00$ \\
\hline Coagulopathy & 3454 & 21.3 & 4539 & 25.2 & 249 & 26.6 & 170 & 28.9 & 160 & 24.8 & 290 & 35.2 & $<0.00$ \\
\hline$y_{p}$ & 4594 & 28.3 & 4 & .9 & 165 & 17.6 & 50 & 8.5 & 155 & 24.0 & 105 & 12.7 & $<0.001$ \\
\hline Chronic liver disease & 373 & 2.3 & 462 & 2.6 & 20 & 2.1 & 30 & 5.1 & 15 & 2.3 & 31 & 3.8 & $<0.00$ \\
\hline Fluid and electrolyte dis & 4492 & 27.7 & 4297 & 23.8 & 333 & 35.5 & 165 & 28.0 & 196 & 30.3 & 210 & 25.5 & $<0.001$ \\
\hline $\begin{array}{l}\text { Pulmonary circulation } \\
\text { disorders }\end{array}$ & 680 & 4.2 & 600 & 3.3 & 25 & 2.7 & 45 & 7.6 & 30 & 4.6 & 25 & 3.0 & $<0.00$ \\
\hline Tob & 3268 & 20.2 & 6369 & 35.3 & 160 & 17.1 & 195 & 33.1 & 105 & 16.3 & 239 & 29.0 & $<0.00$ \\
\hline Histo & 2638 & 16.3 & 3839 & 21.3 & 95 & 10.1 & 95 & 16.1 & 90 & 13.9 & 164 & 19.9 & $<0.001$ \\
\hline History of CABG & 2033 & 12.5 & 5822 & 32.3 & 55 & 5.9 & 65 & 11.0 & 70 & 10.8 & 245 & 29.7 & $<0.001$ \\
\hline Prior myocardial infarction & 1591 & 9 & 2900 & 16.1 & 80 & 8.5 & 80 & 13.6 & 60 & 9.3 & 85 & 10.3 & $<0.0$ \\
\hline Trans-femoral TAVR & 12,601 & 77.8 & 14,933 & 82.9 & 803 & 85.6 & 505 & 85.6 & 476 & 73.6 & 571 & 69.2 & $<0.001$ \\
\hline Trans-apical TAVR & 3630 & 22.4 & 3139 & 17.4 & 135 & 14.4 & 85 & 14.4 & 171 & 26.4 & 254 & 30.8 & $<0.00$ \\
\hline
\end{tabular}

$C K D$ chronic kidney disease, $A A$ African American, $P C I$ percutaneous coronary intervention, $C A B G$ coronary artery bypass grafting

knowledge by examining other ethnicities and evaluating gender differences as well. Further, we demonstrated ethnic and gender disparities in the adjusted in-hospital mortality rate, which was highest among Hispanic men followed by Caucasian women.

The background for ethnic disparities in the uptake of TAVR is multi-factorial. Socio-economic status and insurance coverage play important roles in preventing certain groups from receiving TAVRs. Reports from the United States Census Bureau suggested higher rates of non-insurance among minorities; reaching
$10.5 \%$ in AA and $16 \%$ among Hispanics compared with $6.3 \%$ among Caucasians [5]. Cultural differences may also play a role, with reports of higher propensities to refuse invasive treatments among some minorities compared to Caucasians [6]. Importantly, minorities have been underrepresented in major clinical trials and specifically for TAVR [1].

This analysis is limited by the data source, which is an administrative database, and liable to documentation errors. Also, the NIS provides only data related to the index hospitalization, with no available long-term data. Being an 
A

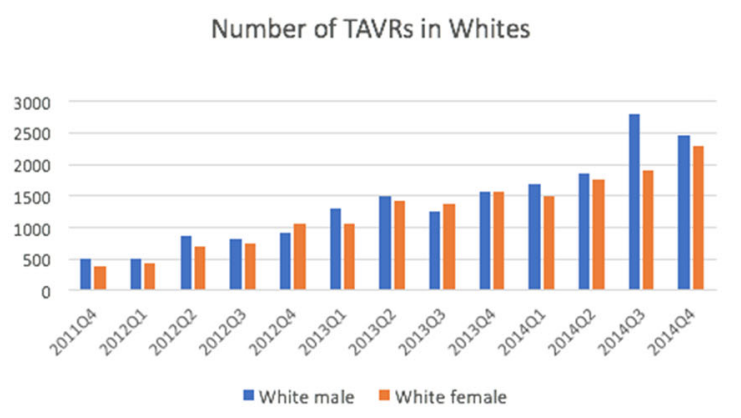

B Number of TAVRs in AA and Hispanics

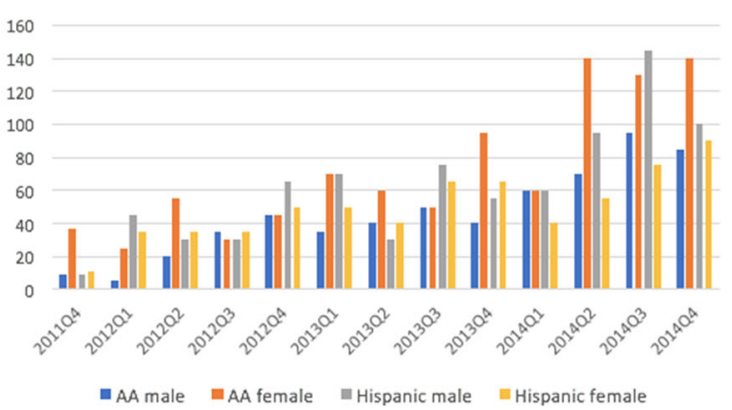

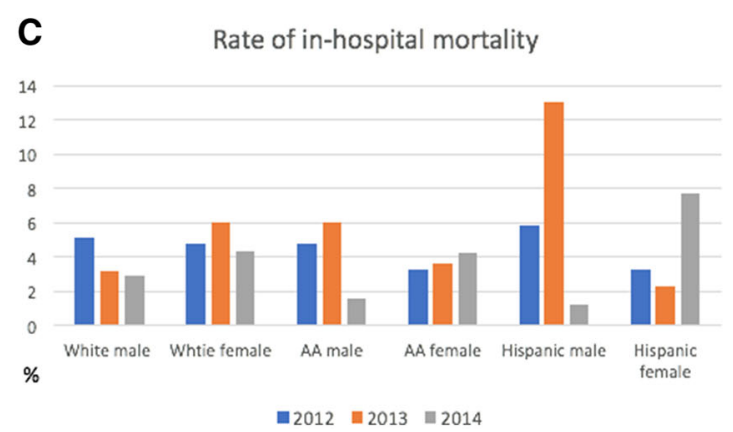

Fig. 1 Trends in number of TAVR procedures and the rate of in-hospital mortality among Caucasians, African Americans, and Hispanics

observation study, there is always potential for selection bias. However, we attempted to reduce allocation bias by conducting multivariable regression analyses. Useful information, such as medications, laboratory data, as well as type of TAVR valves, was unavailable through this database. Further studies are encouraged to identify barriers for uptake of TAVR by minorities, as well as to better specify ethnic and gender differences in outcomes of TAVR procedures.

\section{ACKNOWLEDGEMENTS}

Funding. No funding or sponsorship was received for this study or publication of this article.

Authorship. All named authors meet the International Committee of Medical Journal Editors (ICMJE) criteria for authorship for this article, take responsibility for the integrity of the work as a whole, and have given their approval for this version to be published.

Disclosures. Ayman Elbadawi, Syed Yaseen Naqvi, Islam Y. Elgendy, Mohamed F. Almahmoud, Mohamed Atef, Hesham Abowali, Gbolahan O. Ogunbayo, Hani Jneid, Khaled M. Ziada have nothing to disclose.

Compliance with Ethics Guidelines. This article does not contain any studies with human participants or animals performed by any of the authors.

Data Availability. All data generated or analyzed during this study are included in this published article/as supplementary information files.

Open Access. This article is distributed under the terms of the Creative Commons Attribution-NonCommercial 4.0 International License (http://creativecommons.org/licenses/ by-nc/4.0/), which permits any noncommercial use, distribution, and reproduction in any 
medium, provided you give appropriate credit to the original author(s) and the source, provide a link to the Creative Commons license, and indicate if changes were made.

\section{REFERENCES}

1. Smith CR, Leon MB, Mack MJ, Miller DC, Moses JW, Svensson LG, et al. Transcatheter versus surgical aortic-valve replacement in high-risk patients. N Engl J Med. 2011;364(23):2187-98.

2. Leon MB, Smith CR, Mack MJ, Makkar RR, Svensson LG, Kodali SK, et al. Transcatheter or surgical aorticvalve replacement in intermediate-risk patients. N Engl J Med. 2016;374(17):1609-20.
3. Zack CJ, Al-Qahtani F, Kawsara A, Al-Hijji M, Amin $\mathrm{AH}$, Alkhouli M. Comparative outcomes of surgical and transcatheter aortic valve replacement for aortic stenosis in nonagenarians. Am J Cardiol. 2017;119(6):893-9.

4. Holmes DR, Nishimura RA, Grover FL, Brindis RG, Carroll JD, Edwards FH, et al. Annual outcomes with transcatheter valve therapy: from the STS/ACC TVT registry. J Am Coll Cardiol. 2015;66(25):2813-23.

5. U.S. Census Bureau; 2017. https://www.census.gov/ data/datasets/2017/demo/popest/nation-detail.html. Accessed April 2019.

6. Groeneveld PW, Kruse GB, Chen Z, Asch DA. Variation in cardiac procedure use and racial disparity among Veterans Affairs Hospitals. Am Heart J. 2007;153(2):320-7. 